Article

\title{
Pathways to the Professoriate: The Experiences of First-Generation Latino Undergraduate Students at Hispanic Serving Institutions Applying to Doctoral Programs
}

\author{
Andrew Martinez \\ Graduate School of Education, University of Pennsylvania, 3819 Chestnut Street, St. Leonard's Court, Suite 140, \\ Philadelphia, PA 19104, USA; andmar@gse.upenn.edu
}

Received: 26 January 2018; Accepted: 21 February 2018; Published: 2 March 2018

\begin{abstract}
Despite representing the largest ethnic minority group in the United States, Latinos remain underrepresented in the professoriate. Although Latinos are increasingly attending college, fewer graduate and even fewer continue to pursue graduate school. Prior research has explained the challenges that first-generation college students encounter in post-secondary contexts. Given that Latino college students are likely to be first-generation, understanding the experiences of first-generation Latino undergraduate students who aspire to be professors and are applying to graduate school can help illuminate what factors help support this underrepresented group in pursuing a career in the academy. Using qualitative approaches, this study describes the experiences of 15 first-generation undergraduate Latino students in a grant funded academic program that provides them with a plethora of resources to help prepare them for graduate school applications. The findings suggest how early exposure to information about applying to graduate school, access to role models, familial support and understanding of an academic career and having a community of peers with similar ambitions can help cultivate an environment where first-generation, Latino students remain inspired and committed to pursuing graduate school in efforts to become a professor.
\end{abstract}

Keywords: Minority Serving Institutions; Hispanic Serving Institutions; students; faculty; first-generation; mentoring

\section{Introduction}

First-generation Latino college students are at a higher risk for not completing a postsecondary degree when compared to other racial and ethnic minorities due to the added challenges of being the first to go to college. Thus, first-generation Latinos are underrepresented in graduate school, especially among doctoral programs. Research suggests that first-generation students begin college less academically prepared, report having lower educational expectations than their peers [1], apply and attend less selective colleges that are closer to home [2] and are likely to perceive less support from their families for attending college [3]. These findings explain why first-generation students are more likely to drop out of college [3] or take longer than six years to complete a degree [4]. Latinos are more likely than their peers to be first-generation accounting for more than one third of these students $(38.2 \%)$ [5]. Given the low attainment rates for this group, Latinos are underrepresented in graduate school and are less likely to pursue a doctoral degree.

Disaggregating data to focus on doctoral recipients within the humanities and social sciences reveal that of the 10,572 doctorates conferred in the U.S. in 2012 , only $8.1 \%$ (860) were awarded to Latinos [6]. Although data suggest that Latinos are receiving doctoral degrees at higher rates than ever before [5], challenges remain with producing Latino faculty. One of the most common challenges 
that first-generation undergraduate Latinos who consider pursuing a career as an academic encounter is the lack of representation of their racial and ethnic identity within the professoriate, which has an effect on their self-confidence in being able to pursue this ambition [7]. First-generation undergraduate students who aspire to become professors encounter challenges of discussing the value of academia to their families [3] causing them to question whether pursuing graduate school is worth it at all.

Using a qualitative approach, this study gives voice to the experiences of first-generation, Latino students who aspire to become professors in the humanities. Discussing how their interest in pursuing a doctoral degree developed and evolved over time, the scholars interviewed for this study reveal the experiences and challenges that have created different pathways for them to achieve their goals. Given their experience as the first person in their families to go to college, although they have these goals to become professors, most of them have very little knowledge of graduate school and the academy more broadly. These scholars are all part of a grant funded pipeline program that provides financial, academic and emotional support services, as well as exposure to academic opportunities in efforts to help them all matriculate into doctoral programs in the humanities.

\section{Background}

Latinos account for only $4.1 \%$ of the professoriate in the U.S. [8]. As demographics in the U.S. continue to shift, with Latinos rapidly becoming the new majority [9], it is important that the academy in higher education mirror the makeup of our country. To do this, we must graduate more Latinos with doctorates and support their success in the academy. To effectively support the success of first-generation, Latinos aspiring to enter doctoral programs in the humanities, cultivating an environment where these students have the social capital and knowledge necessary to navigate graduate school is essential. For first-generation, Latino students, these spaces are new to them and attention to their socialization and academic development before transition to graduate school can play a major role in their success and ability to achieve their goals. Furthermore, some first-generation, Latino students may have family that is supportive of their academic goals but skeptical about the amount of time it takes, especially if the student moves far from home [10]. These types of challenges can play a significant role on the individual student, thus special attention as to how these students navigate that tension can inform our understanding of how these students persist through the challenges of being first-generation Latino students applying to doctoral programs.

Since underrepresented ethnic minorities in postsecondary contexts are likely to be first-generation [11], research on the socialization of first-generation Latinos is needed to understand how we can increase the Latino professoriate. Given that Hispanic Serving Institutions (HSIs) educate $56 \%$ Latinos (NCES) in the U.S., many of whom are first-generation, research in how HSIs serve this population can help inform what is best suited to supporting this cohort, or what else should be done to further support this population. As the Latino population continues to grow, their enrollment into postsecondary education is increasing too. Thus, research on the challenges first-generation Latinos encounter at HSIs and how they overcome these challenges are important to improving the ways in which HSIs educate these students. These institutions receive federal funding specifically for serving low-income, Latino students, many of which are considered first-generation college students.

\subsection{The Role of Hispanic Serving Institutions}

Hispanic Serving Institutions developed in response to the demographic shifts in the nation. The federal government defines HSIs as institutions with at least $25 \%$ low-income Latino students [12]. Unlike Historically Black Colleges and Universities (HBCUs) that developed as the only option for education for Black students during segregation, HSIs are institutions that had originally served White students but their Hispanic population increased. This federal designation comes with additional federal funding to help support them in increasing the degree attainment of Latino students. Many of these institutions have specific initiatives that aim to improve the retention, support and graduation of their Latino students through culturally relevant and evidence based practices that have been seen 
to be effective in supporting Latino students both inside and outside the classroom. Representing some of the most diverse post-secondary institutions in the U.S. in terms of both students and staff and faculty, HSIs offer their Latino students same-race role models, cultivate inclusive environments that enhance their students' learning and prepare their students to succeed in the workforce or in graduate and professional education. Since HSIs educate such a large proportion of Hispanics in postsecondary education, many of whom might not attend college otherwise, it is important to invest in these institutions to best serve the growing population of Latino college students.

\subsection{HSI Pathways to the Professoriate Program}

Research has suggested that the doctoral student experience is influential in shaping one's aspirations and qualification into becoming a faculty member [13]. Given that HSIs educate such a large population of Latino students in higher education, the Penn Center for Minority Serving Institutions (CMSI) developed a program specifically for HSIs. The HSI Pathways to the Professoriate Program, a \$5.1 million grant supported by the Andrew W. Mellon foundation, is structured to provide the necessary support that enables the scholars selected for the program to persist through graduate school with aspirations towards becoming professors in the humanities. Informed by research on Latino student achievement and graduate student socialization, scholars selected for the program have access to a plethora of resources aimed to support their aspirations to becoming faculty. These resources include: faculty and graduate student mentorship, a focus on the graduate school application process, opportunities to conduct and present research, funding for research and graduate school applications and dedicated staff to support students within the program.

The CMSI selected Florida International University, California State University, Northridge and The University of Texas at El Paso as the three partner HSI institutions. In conceptualizing the grant, CMSI and the Mellon Foundation discussed having a program that had a wide-reach and national impact, thus the institutions selected are located in different regions of the U.S. (Florida, California and Texas) and have a large population of Latinos. The five partnering research institutions are New York University, University of Pennsylvania, University of California, Berkeley, Northwestern University and University of California, Davis. These institutions have strong humanities PhD programs and have agreed to help serve a mentorship role for the selected scholars as well as provide support for the students in their efforts to apply to different doctoral programs. Over the next 5 years, 90 students (30 from each HSI) will be selected for the program. Each cohort consists of 30 students-10 from each HSI. The fellows are selected during their junior year. Upon acceptance, they receive a graduate student mentor, faculty mentor, support from the HSI coordinator, a mentor through the CMSI, along with financial, programmatic and academic support that is provided through the activities from the program. During the summer before their senior year, participants of the program will attend a research intensive and graduate school application preparatory summer program, featuring faculty from the partnering research institutions. Throughout their time in the program, the scholars participate in monthly webinar calls with a research associate from the CMSI to talk about their experiences within the program. These video calls allow the fellows to share the challenges they are overcoming from their experiences as aspiring professors in efforts to learn from each other and extend the relationships being built beyond their institutional cohort.

\section{Literature Review}

According to Ravitch and Riggin (2017), "conceptual frameworks seek to identify 'presumed relationships' among key factors or constructs to be studied and that the justification for these presumptions may come from multiple sources such as one's own prior research or 'tentative theories' as well as established theoretical or empirical work found in the research literature" [14] (p. 8). By reviewing literature on Latino student success, the challenges and experiences of first-generation students in postsecondary education contexts and best practices in socialization of graduate students, 
the conceptual framework contextualizes the study by establishing the importance of a growing Latino professoriate and the conditions that should exist to help maintain that growth.

\subsection{Socialization of Graduate Students}

This study situates the experiences of first-generation Latino undergraduates participating in the HSI Pathways to the Professoriate Program within the Weidman, Twale and Stein Graduate Socialization Framework [15]. Socialization in graduate school has largely been defined as the process in which an individual learns and adopts the values, skills, attitudes, norms and knowledge necessary for entry into a professional career within a specific field $[16,17]$. Socialization for graduate students occurs in four distinct developmental stages: Anticipatory, Formal, Informal and Personal [15]. During the anticipatory stage, students begin to learn the culture, values, norms and expectations of graduate school and the academy [16]. These students become cognizant of the behavioral and cognitive expectations of their field [15]. The formal stage involves graduate students receiving "formal instruction in the knowledge upon which future professional authority will be based ... Students are inducted into the program, practice role rehearsal and thereby determine their degree of fitness, observe and imitate expectations through role taking and become familiar faces in the program" [15] (p. 13). The informal stage involves students learning the informal role expectations through their interactions with older students and professors [15] where graduate students observe behavioral cues and act accordingly [16]. The personal stage refers to the phenomenon where "individuals and social roles, personalities and social structures become fused" [17] (p. 880) and students part from their former ways [15]. At this point, students begin to focus on specific research interests and become more involved with publishing, presenting and service [15].

However, unlike the model suggests, other researchers have posited that this socialization can occur during undergraduate study too and it is through this socialization process that students decide to pursue graduate study [18]. In a study exploring the experiences of aspiring graduate students in a summer bridge program, McCoy and Winkle-Wagner argued, "the anticipatory socialization process begins during a student's undergraduate education. It is during this period that the aspiring scholar begins the development of a scholarly habitus" [18] (p. 425).

Most theories focused on the socialization undergraduate and graduate students were developed at times when the graduate student population was overwhelmingly male and White [19], thus these theories are not nuanced enough to account for the increasingly diverse populations in postsecondary education contexts today. To address this normativity, aspects of Yosso's (2005) conceptualization of community cultural wealth will add some perspective to explain the structure of the HSI Pathways to the Professoriate Program (Pathways) and to analyze the experiences of the students in this study [20].

Yosso's community cultural wealth model places value to forms of capital that are otherwise not acknowledged. This capital can be used in as a form of currency in educational settings and can lead to confidence building and a positive scholarly identity formation. Research about underrepresented ethnic minorities, especially in education, are overwhelmingly deficit-oriented, focusing on what these populations lack, instead of how they succeed despite the inequitable resources and capital they have access to. To combat this, Yosso argued that cultural capital is not just inherited by the middle class but it also refers to the acquisition of knowledge, skills and abilities that are valued those who are privileged in society [20]. In a qualitative study following low-income, first-generation students pursuing doctoral degrees, Gardner and Holley found that first-generation students recognized and utilized their resilience capital to overcome obstacles during graduate school like navigating conversations with their families, which this study suggests students decide to distance themselves or not share much of their experiences during their time in graduate school [21].

\subsection{Familial Expectations \& Support of First-Generation Latino College Students}

Olive notes that first-generation students make choices based on different worldviews than continuing-generation students and that these views frame how they perceive and value postsecondary 
education [22]. These students tend to have lower educational aspiration than students whose parents attended college [23]. Furthermore, parents who did not attend college tend to have less direct knowledge of the economic and social benefits of earning a postsecondary degree. Thus, some parents of first-generation students prefer that their children work rather than pursue a postsecondary degree. For first-generation students who come from immigrant backgrounds, a common expectation of their family is to continue to live at home and carry out family duties while attending college [24,25]. This may complicate their ability to do well as they are likely to not be as academically prepared as their non-first-generation counterparts and thus must juggle their familial responsibilities along with adjusting to the rigor of college coursework. For those that do go on to doctoral programs, many encounter push back from their families who expect them to contribute to the family household through working and being around the family [26].

A substantial amount of research indicates that first-generation students perceive a lower level of family support and less knowledge of the college environment from their parents [22,23,27]. This is important to consider since other research has suggested that parental encouragement, involvement and overall support are some of the most significant predictors of postsecondary educational aspirations [28].

\subsection{Supporting First-Generation Aspiring Professors through Pipeline Programs}

Academic support and pipeline programs for underrepresented ethnic minorities are designed to increase enrollment, retention and graduation rates of these populations. Research suggests that first-generation students have lower retention rates as undergraduates [29], thus many schools and organization develop programs to address this cohort's attrition [22]. These programs help participants to acquire different forms of cultural capital so that these students can navigate their time in college successfully, realizing their potential and emerging scholarly identities. In a study examining the effects of participating in a summer bridge program for first-generation aspiring graduate students, researchers found that participating in summer bridge programs "led to increased confidence in the participants' abilities to succeed as scholars ... this confidence shaped the students' perceptions that becoming a scholar was a feasible option for them, implying a change in their habitus, or the set of actions they deem viable" [17] (p. 432). In a study on the McNair Scholars program, a pipeline program for low-income and/or underrepresented students, it was shown that participating in these types of programs allow for students to begin their socialization process as undergraduates as they become aware of the norms of pursuing graduate student, especially when given opportunities to produce original research and work directly with faculty [30]. Using qualitative approaches, Gittens found that these types of programs promote preparation for graduate socialization, build self-confidence, an academic identity and social and academic connectedness [30].

Olive notes that academic support programs, much like summer bridge programs described in McCoy and Winkle-Wagner's study [17] and the Pathways program, "[provide] a very viable strategy with dealing with at-risk college students. These programs address not only academic concerns but also the cultural, social, physical and emotional aspects of the students' well-being" [22] (p. 86). In terms of socialization, program participants are able to get the academic support they need to be successful along with the opportunity to build their confidence as an emerging scholar.

This study is focused on how the Pathways program provides its participants with opportunities to develop a scholar identity, acknowledge the capital that they bring with them and begin the socialization process into graduate school and the academy so that they are successful as aspiring professors. The guiding perspectives of this study, Weidman, Twale and Stein (2001) Graduate Socialization Framework and Yosso's (2005) idea of community cultural wealth, collectively justify and explain the way in which the Pathway program is set up to provide support to its participants. These frameworks allow for a thorough analysis of the experiences first-generation Latino students in the HSI Pathways to the Professoriate Program. 


\section{Methods}

Using a phenomenological approach to qualitative inquiry, this study focuses on describing the lived experiences of the participants of the study [31]. Phenomenological approaches allow the researcher to study what participants experienced, how they experienced it and the meaning making of their shared experiences [32]. In this study, I explored how the participants' aspirations to becoming professors in the humanities developed, to what extent does their participation in the HSI Pathways to the Professoriate Program help them reach their ambitions, what barriers or challenges they experience as low-income, first-generation students at an HSI in pursuing their goals and how they persist despite these barriers or challenges. I am interested in understanding how low-income, first-generation self-identified Latino students experience this pipeline program aimed to prepare them for matriculation into doctoral programs in the humanities. My research questions are:

1. What are the experiences of first-generation Latinos participating in the Hispanic Serving Institutions: Pathways to the Professoriate Program who aspire to become professors in the humanities?

2. How do first-generation Latinos participating in the HSI Pathways to the Professoriate program overcome the challenges and barriers that they encounter along the process of applying and matriculating into doctoral programs in the humanities?

\subsection{Participation Selection and Selection Criteria}

The HSI partner institutions-California State University at Northridge (CSUN), University at Texas at El Paso (UTEP) and Florida International University (FIU) - have already selected their first cohort of scholars. Each institution has chosen 10 students who aspire to become faculty members in the humanities. This specific study is part of a larger, longitudinal study of the experiences of Latinos at HSIs who aspire to become faculty that are part of the HSI Pathways to the Professoriate Program. To identify participants to participate in this study specifically, all participants in the program were asked to fill a demographic survey. Table 1 provides information of participants that met all criteria (being first-generation college students and self-identifying as Latino, Hispanic, or a specific identity that falls under Hispanic) whose interviews were used for the purpose of this study.

Table 1. HSI Pathways to the Professoriate First-Generation Latino Program Participants.

\begin{tabular}{cccccc}
\hline Pseudonyms & Gender Identity & Racial or Ethnic Identity & Hometown & Institution & Major \\
\hline Alma & Woman & Latina & Havana, Cuba & FIU & English \\
Brandon & Man & Mexican-American, Latino & Ventura, California & CSUN & Sociology \\
Christina & Woman & Xicana & Los Angeles, California & CSUN & Deaf Studies \\
Erica & Woman & Mexican & Van Nuys, California & CSUN & History \\
Erin & Woman & White/Mexican & El Paso, Texas & UTEP & English \& American Literature \\
Gina & Woman & Hispanic & Los Angeles, California & CSUN & English Literature \\
Javier & Man & Mexican American & Los Angeles, California & CSUN & Philosophy \& Religious Studies \\
Justine & Woman & Chicana & El Paso, Texas & UTEP & Chicano Studies \& History \\
Lisa & Woman & Mexican-American & El Paso, Texas & UTEP & English \& American Literature \\
Kendra & Woman & Mexican American & North Hollywood, California & CSUN & Psychology \& Chicana/o Studies \\
Maya & Woman & Hispanic & Queens, New York & FIU & English \\
Mateo & Man & Hispano & El Paso, Texas & UTEP & History \\
Mark & Man & Spanish \& Cuban American & Miami, Florida & FIU & English \\
\hline Sylvia & Woman & Salvadorian & Los Angeles, California & CSUN & Linguistics \& Chicana/o Studies \\
Vincent & Man & Hispanic/Latino & El Paso, Texas & UTEP & Art History \\
\hline
\end{tabular}

\subsection{Data Collection}

I collected data by conducting semi-structured interviews, analyzing surveys that participants in the program have filled, recorded monthly webinars among participants, as well as observations.

For the purposes of this study, I analyzed the Interviews of self-identified Latino first-generation students at each of HSI partner institutions $(n=15)$. The goal of the interviews is to understand the first-hand experiences of these scholars in being part of the first cohort of the program.

I interviewed the participants of this study during the first annual summer site visits where representatives from the Penn CMSI visited each of the partner institutions to learn more about the 
Pathways from the student fellows and staff and faculty affiliated with the program. The students have been in the program for about 6 months. During the time of the interviews, the scholars were participating in a research-intensive summer seminar where they worked on individual research assignments, applications for graduate school, GRE preparation and participated in several seminars focused on integrating theory to their writing. During these visits, time was scheduled for each participant to participate in an interview. These interviews ranged between $30 \mathrm{~min}$ to an hour and were recorded and transcribed verbatim. The questions asked started off broad to get to know the participants with questions like: "Tell be about yourself, your experiences in education, your family, etc." After getting a better understanding of the participants' life and experience in education, they were asked questions about how they learned about the program and why they applied to the program, what they are most nervous about in pursuing a doctoral degree, how supportive are their family and friends in regard to their ambition, etc. This was the first of several interviews, as part of the larger study is to interview all participants in the program the summer of their junior year, the Spring of their Senior year and then throughout their time in graduate school.

Beyond the transcripts from the interviews, I took notes during site visits on my observations. The participants also participated in monthly video webinars with a member of the CMSI team to discuss their progress, develop some skills or techniques to aid in applying to graduate school or working on a research project and to cultivate a community among all those involved in the program. These webinars were conducted over the BlueJeans video platform, which allowed for the video feed to be recorded.

\subsection{Data Analysis}

To analyze the data collected from the interviews, I referred to my notes, which represent my reflections and observations immediately after the interviews. I also listened to the recorded interviews again and jotted down notes and reviewed the transcribed interviews. After reading the transcriptions, I coded the data by generating themes that emerged through the interviews. I used NVivo coding, as described by Miles, Huberman and Saldaña which "uses words or short phrases from the participant's own language in the data record as codes" [33] (p. 74). This method honors the participants' voice, which is ideal in phenomenological approaches and seemed most appropriate to not only use the voices of the participants in the coding process but also pay special attention to shared experiences of the scholars through the codes that were generated. The coding process allowed me to see how prevalent some of the themes that emerged are in the study, which allowed me to understand how we make meaning of the experiences of the scholars interviewed and whether their participation in the HSI Pathways to the professoriate program is helping them with their aspirations of becoming professors in the humanities.

\section{Limitations}

There are several limitations to this study. The program is in its second year, so the interviews will only reflect the experiences the scholars are having as rising seniors in college interested in applying to doctoral programs. The interviews will be used to generate themes on their experiences thus far and the effectiveness of their participation in preparing them to apply to graduate school. This study will not be able to fully address the effectiveness of the program as there will not have been a cohort who has applied and matriculated into a doctoral program. Lastly, the data from the study will come from primarily from the interview of the participants. Surveys will be sent to collect demographic and informative data about the participants and their institutions and observations will be noted throughout the study but I will not be interviewing professors, mentors, or family members about their interactions with the participants. As with other qualitative approaches, this study will not yield results that are generalizable but instead, will allow me to make claims about the specific program being studied and implications that may have on how we understand how pipeline programs can help socialize first-generation, low-income Latino students in academic spaces. These findings will help 
improve the program of focus and will add to the research on supporting aspiring first-generation Latino students, particularly those who aspire to earn doctoral degrees.

\section{Findings and Discussion}

\subsection{Development of Academic Interests Tied to Identity}

Many of the participants connected the development of their academic interests and aspirations to becoming a professor with the blooming curiosity of their racial and ethnic identity. For example, Justine began college wanting to pursue a science major with the hopes of finding a lucrative career but claims her life changed after taking a Chicana literature course. For the first time in her life, she was learning about herself. She said, "When I started to read this literature I started to realize that I was written into here and that it was a culture that my grandmother gave me that was here, that I had been denied." As a Mexican born and raised in El Paso, Texas, Justine had learned to adopt American culture as her own and to not explore or portray her Mexican culture. By taking courses in Chicana literature, she met professors and other scholars who were able to connect her with parts of her own identity that she was aware of but did not have a chance to explore. Justine shared that her Chicana literature professors inspired her to consider graduate school and learning more about her identity in the classroom has influenced her decision to becoming a professor. Other fellows saw a career in the academy as a way to marry their academic interests with the ability to educate and inspire other students like them. Kendra, a Chicano studies and psychology double major, was frustrated with her psychology coursework because the absence of culture within the curriculum. By adding Chicano studies as a major, she saw a way to bridge the two disciplines to focus on mental health in Latino communities. She said, "to me, wanting to become a faculty member, I want to create that space where I can have students from Latino/Latina backgrounds but they're not only talking about Chicano studies, they're not only talking about history or culture." She would like to inspire students like them to see the merit in using their identity and culture as a lens to understand whatever other fields that interests them, similar to what she is experiencing by double majoring.

Former professors also made a lasting impression on many of the fellows, sometimes introducing the idea of the fellow to consider graduate school and becoming a professor. Diagnosed at an early age with anxiety, Alma attributed her love for literature after discovering the power it had in healing. Seeing what an impact literature had on her, she decided to major in English at FIU, where she was inspired to become a professor after having such wonderful experiences with her professor. She attributed her decision to apply to the Pathways program to her English professor. She said, "I did because of her ... I wanted to be a professor because of her, because I didn't know before. I wanted to major in English. That's all I knew. I didn't really know my career path after. I had two classes with her that first semester and I loved her, I loved the way she taught." Other cohort members from FIU were also inspired by this particular faculty member who introduced and inspired them to consider a career as a professor after seeing how passionate they were towards literature and theory. Maya, also at FIU, was inspired by one of few women of color professors that she had. Grateful for the type of readings this professor assigned, Maya shared that when she becomes a professor, she will include inclusive and relevant literature that reflects the experiences of her students so that they too can be inspired or empowered to consider academia like she was.

Eva, who initially wanted to go to culinary school after graduating high school, pursued a bachelor's degree at UTEP after her mother told her she needed a bachelor's degree before culinary school. She decided to pursue anthropology where she was introduced to food studies and was encouraged by one of her faculty members and mentors to consider graduate school in anthropology and food studies given her passion for the culture and stories behind certain dishes and Eva's commitment to educating the community on food. It was through this particular professor's mentorship that Eva realized how this career path combined her growing interests in culture and food and the ability to teach and inspire others in her community. 
These students, although unbeknownst to them, all demonstrated having aspects of aspirational capital that have motivated them to seek out opportunities to learn more about becoming professors. Their lived experiences, coupled with the support structures set in place at their institutions, has led them to learn about how the Pathways program can help support their endeavor of becoming professors in the humanities.

\subsection{Familial Support Despite Lack of Understanding}

The pressure of being the first in the family to attend college was mentioned in several of the interviews but for the most part, this was a motivational factor. These students explained how although it was difficult to navigate at times, their academic pursuits were a source of pride for their families. While all the fellows interviewed had the support to pursue graduate study, many of them also shared that their families did not quite understand their studies, the decision to pursue graduate school after earning a bachelor's degree, or why their particular child was excited to be part of the Pathways program. For example, when Brandon reflected on the day he was accepted into the program he shared, "there's always kind of, not a language barrier but some kind of barrier with trying to get my parents to understand what this all entails and what a big deal it was. They were happy but they didn't really know how to express it or anything." Maya had a similar experience, which she attributed to her identity as a first-generation student whose mother was not involved when she was applying to college or transitioning to college because she simply did not know how she could help.

For the students who have supportive families that do not quite understand their field of study or why they need to go to graduate school, they are frequently thinking of ways to, as Sylvia says, "translate the field" to their families to lessen the amount of uncertainty their parents have. However, this can become challenging for some of the students who are pursuing ethnic studies or Chicano literature and have parents who believe that they should assimilate more into American culture. Justine, who was born and raised in El Paso, Texas and whose family does not want her to go far away from home, shares that her mother was very against her pursuing Chicano studies as a major because she associates that term with gangsters instead of Mexican-Americans who are fighting for social justice. Growing up in a household where she was encouraged to erase her Mexican identity and be proud of her American identity, Justine felt that her mother was supportive of her participating in the Pathways program because she wants Justine to be happy and because of the prestige associated of being a Mellon fellow but her mother does not understand why Justine would want to focus on Chicano studies. Despite these types of tensions of leaving home or pursuing an academic field that is not well-received or understood by their parents, all the students in the program feel that they have the support that they need from their family to participate fully in the program.

\subsection{Knowledge of Pursuing Graduate Study}

The initial interviews were conducted during the Pathway's fellows research-intensive summer seminar where they participated in lectures about theory, worked on preparing graduate school applications and studied for the GRE. During these interviews, most of the scholars revealed that they were unaware of the academic rigor and expectations of graduate school. While many of them were academically competitive at their institutions, the preparatory work provided through the summer seminar challenged them in ways that they were not accustomed to with their undergraduate coursework. When reflecting on the summer seminar experience, Kendra, a junior at CSUN said, "I've never had a class like that. I've never had a seminar ... . I think I'm being challenged to finally speak up and say my ideas, ask my questions ... I'm so used to having lectures where the professor is so quick that they kind of zoom my questions, where as of right now in the seminar-like environment, I need to understand that my questions and my ideas are going to be valued." Brandon, another junior for CSUN, had aspirations of earning a PhD as a community college student but had trouble finding information about how to prepare and apply to doctoral programs until he came across information about the HSI Pathways to the Professoriate program. Once accepted into the program, he learned 
about the different types of research institutions and what that meant in the types of resources these institutions have.

Lisa, a student at UTEP, thought that graduate school was solely focused on the topic of interest of the student. She shared, "Prior to coming into this program, I thought it was just going to be like taking classes and writing a thesis ... I didn't know how very intense a PhD was going to be and ... I had no idea about the coursework and the comps you have to take. I had no idea about that, so that was all very new to me... I didn't really know the structure of how you get a PhD, what things you have to do to get one. I knew the dissertation of course but I thought that was all you do in that time." Considering that admission committees consider an applicant's knowledge of the process, the structure and expectations of graduate school are essential for applicants to demonstrate their preparedness for admission. Javier, another student from CSUN, upon his acceptance into the Pathways program began feeling overwhelmed. He said, "knowing academia was limited until I actually got into my first classroom in community college but even then, it didn't really dawn onto me, until this program started." He goes on to discuss how taking a diagnostic GRE test and learning from our research institution partners that lectured in his summer seminar instantiated how unaware and unprepared he was which led to him wanting to take full advantage of the resources and support made available by the Pathways program.

\subsection{Community of Peers}

The students at all three institutions were appreciative of the diversity of academic interests within the cohort and the supportive nature that has been cultivated within the program. For many of these students, this cohort community has provided them with a community of academic inquiry that they do not have with their peers outside of the program or their family. Reflecting on a field trip to an academic conference, Brandon shared:

On the way back, I was on the train with five other people in my cohort and we were just having an interdisciplinary discussion and it took us everywhere. It took us from the meaning of like, like everything being an illusion, you know, God, politics, everywhere and I just loved [it]. I felt like a real academic and that's where I really felt myself shine, where we had somebody in philosophy who does Latin American philosophy, linguistics, ethnic studies, myself, sociology, religious studies and there was overlap in our theories. It felt so natural. It felt incredible, honestly and getting to know each of them and their struggles and how motivated they are. Their wins are my wins and I feel like truly like a blossoming of true friendship with them.

Being able to have both an academic and casual conversation on life, or particular topics in a certain field, has shown Brandon and others in his cohort the importance and benefit of belonging to a community. Christina spoke about how she and other members of her cohort created a group text through the GroupMe phone application where the cohort from her school (CSUN) encourage each other through hard times, have sporadic intellectual conversations, or simply plan informal gatherings with each other to take a break from their studies. She notes that although some of them may indeed be applying to the same $\mathrm{PhD}$ programs, the community they built is not competitive and instead they have become highly supportive and encouraging towards each other.

The seminars that these scholars attending during the summer are research intensive and heavy on theory. Many of the scholars appreciate how helpful they are among each other when a particular theory or idea is hard to understand. Justine, for example, shared that learning about Critical Race Theory was fascinating because she felt that her ideas and identity were being erased by the White race and learning about this theory aligned with her thoughts. She came to appreciate her cohort more when she saw how intrigued they were by Critical Race Theory and that when she shared how it made her feel, others agreed. 
By having the program structured with cohorts, these scholars were able to form academic and personal relationships with their peers in ways that they were not accustomed to doing with family and other peers. Many of them indicated that they understand that graduate school and the academy can be isolating, especially as a minority, however, their cohort has shown them that it does not have to be. These relationships that they are forming among each other is encouraging them to keep pushing through this process and is a constant reminder to them that they are not alone.

\section{Recommendations for Research and Practice}

While this study revealed the experiences of first-generation, Latino college students in a program aimed to help them to become professors in the humanities, not all institutions are capable of providing the extent of resources that the participants of this program have access to. However, there are first-generation, Latino students who have successfully matriculated into doctoral programs and have become faculty. More research on the experiences of these students can help illuminate how they were able to persist throughout their time in postsecondary education despite the barriers they may have encountered throughout their journey.

Considering the different forms of support that the HSI Pathways to the Professoriate program provides to the students along with the experiences that the first cohort has shared, there are three recommendations for supporting first-generation, low-income Latino students aspiring to become professors. They are: (1) early exposure and support about applying to graduate school; (2) intentional and welcoming relationship with a student's family to help explain the academic career; and (3) cultivating a community of peers.

\subsection{Early Exposure and Support about Applying to Graduate School}

Given the structure of the program, many of the participants shared feeling overwhelmed about the requirements for applying to graduate school, preparing to study for the GRE exam and the rigor of graduate school. Recognizing that not every student has the opportunity to be part of a program like Pathways, institutions who would like support first-generation, low-income students who have aspirations to becoming professors may draw on some of the support structures in Pathways as a way to better serving these students. By meeting with students during their first and second year of college and having conversations about graduate school, students may see the application process as less daunting given that they have more time to prepare and seek resources. The Pathways program has a structured research-intensive summer seminar component that can be adapted and spread out throughout an undergraduate's time in college. Having access to this type of information may help students seek out resources to help support their endeavors earlier in their college career so that by their junior and senior year, they are completing the requirements necessary to apply to graduate school rather than just learning about them.

\subsection{Involving the Family}

It was clear when analyzing the interviews that the students in the Pathways program had supportive parents who were unaware of what the program provides and what a career in the academy entails. CSUN, FIU and UTEP all included activities to engage with the families of their Pathways Cohort. At UTEP, the students and their families were invited to an on-campus barbeque with administrators and faculty affiliated with the program. Although there was no formal program, the families were able to engage with their children's support system at UTEP and learn more about the program and their child's progress. CSUN and FIU included family engagement during the recruitment programming to help explain to families what the program was about as well as the support the selected students would receive.

The familial support of the students involved with this studied varied, however, all students interviewed felt supported by their family. The students, however, did speak about the challenge of having the support of their family despite their parents not understanding what they were actually 
doing. Many of the Pathways scholars shared that their family emphasized the importance of education and were very supportive of them going to college, however, the goal was to earn a bachelor's degree and then get a job. Pursuing an academic career as a professor, however, requires graduate school, which parents were more likely to question. To help alleviate this challenge, institutions can adopt some of the practices these HSIs implemented to engage with the families of their student with an emphasis on exposing and explaining graduate school and academic career paths. By explaining graduate school and the career possibilities after earning a doctorate, first-generation, Latino students, who also will have limited knowledge of the process and career prospects, may be less concerned justifying their decisions to pursue graduate school.

\subsection{Cultivating a Community of Peers}

The bonds created among the students involved in the Pathways program highlight the benefit of creating a peer-network of students interested in pursuing a doctoral degree to become professors. Often not having anyone in their family or friend group to talk about their research interests and their excitement and concerns on what lies ahead, the cohort model within the Pathways program created an environment where the students felt inspired to be a part of a community of intellectuals. Some participants shared that they did not feel alone because they had nine others who they knew had similar experiences as them.

Given that first-generation, Latino students are underrepresented in the professoriate, institutions should make a concerted effort to connect undergraduates who have interests in pursuing a doctoral degree. By connecting undergraduates with similar ambitions to each other, these students have the opportunity to create their own support structure to navigate the process of applying to graduate school.

\section{Conclusions}

As first-generation college students, the scholars in this study had limited knowledge of applying to and completing college and even less knowledge of graduate school and pursuing a doctoral degree. However, these scholars demonstrated the aspirational and resistant capital necessary to not only overcome the challenges that they encounter in their academic pursuits but to use these challenges as motivation to succeed and inspire others. Although their experience as first-generation students was filled with uncertainty and self-doubt, the community built within the cohort and the resources provided through the program have given these students the tools necessary for them to become more confident and prepared to apply and enter doctoral programs. Their ambition to becoming professors in the humanities were tied to the professors that took a special interest in them and encouraged them to consider further study. Many of these scholars were inclined to teach at a young age but did not consider becoming a professor until they were encouraged by one of their own.

To best support the growing population of first-generation Latino students in college, institutions should introduce these students to graduate study early in college so that they have more time to learn more about post-baccalaureate study and become better prepared for the application process. It is important to consider involving the family in these conversations too, so that the student interested in pursuing graduate school has the support of their institution or advisor in explaining the career path to parents who may have never step foot into a college campus. Lastly, cultivating a community of ambitious, first-generation, Latino scholars who all intend to pursue graduate study may be helpful in these students connecting with others who have similar backgrounds and experiences. As the findings suggested, the Pathways cohort has helped the students in the programs understand that it is fine to feel overwhelmed, underprepared and unsure throughout the process and that they are not alone in feeling that way.

Given the Latino population in the United States and its projected growth as the largest ethnic minority group, supporting programs that aim to increase the Latino representation in the professoriate is central to cultivating an environment of success for these students, especially those who are 
first-generation and have less knowledge and support in learning about how to pursue graduate school and careers in the academy.

Acknowledgments: HSI Pathways to the Professoriate is supported by a $\$ 5.1$ million grant from the Andrew W. Mellon Foundation.

Conflicts of Interest: The author declares no conflict of interest.

\section{References}

1. Choy, S. Students Whose Parents Did Not Go to College: Postsecondary Access, Persistence, and Attainment. Findings from the Condition of Education; National Center for Education Statistics, U.S. Dept. of Education, Office of Educational Research and Improvement: Washington, DC, USA, 2001.

2. Engle, J. Postsecondary access and success for first-generation college students. Am. Acad. 2007, 3, 25-48.

3. Thayer, P.B. Retention of Students from First Generation and Low Income Backgrounds. In Opportunity Outlook; U.S. Dept. of Education, Council for Opportunity in Education: Washington, DC, USA, 2000; pp. 2-8.

4. Cahalan, M.; Perna, L.; Yamashita, M.; Ruiz, R.; Franklin, K. Indicators of Higher Education Equity in the United States: 2016 Historical Trend Report; Pell Institute for the Study of Higher Education, Council for Opportunity in Education and Alliance for Higher Education and Alliance for Higher Education and Democracy of the University of Pennsylvania: Washington, DC, USA, 2016.

5. Saenz, V.B. First in My Family: A Profile of First-Generation College Students at Four-Year Institutions Since 1971; Higher Education Research Institute: Los Angeles, CA, USA, 2007.

6. U.S. Department of Education, National Center for Education Statistics, Higher Education General Information Survey (HEGIS). Available online: https:/ / nces.ed.gov/programs/digest/d16/tables/dt16 318.20.asp (accessed on 12 December 2017).

7. Robinson, W.H.; McGee, E.O.; Bentley, L.C.; Houston, S.L.; Botchway, P.K.; Roy, R. Racial and gendered experiences that dissuade a career in the professoriate. In Proceedings of the Research in Equity and Sustained Participation in Engineering, Computing, and Technology (RESPECT), Charlotte, NC, USA, 13-14 August 2015; pp. $1-5$.

8. U.S. Department of Education, National Center for Education Statistics, Integrated Postsecondary Education Data System (IPEDS). Winter 2011-12, Human Resources Component, Salaries Section; See Digest of Education Statistics 2012, Table 299; U.S. Dept. of Education: Washington, DC, USA, 2012. Available online: https: //nces.ed.gov/pubs2014/2014015_3.pdf (accessed on 12 December 2017).

9. U.S. Census Bureau. Projections of the Population by Sex, Hispanic Origin, and Race for the United States: 2015 to 2060. 2015. Available online: https:/ /www.census.gov/population/projections/data/national/ 2014/summarytables.html (accessed on 12 December 2017).

10. Vasquez-Salgado, Y.; Greenfield, P.M.; Burgos-Cienfuegos, R. Exploring home-school value conflicts: Implications for academic achievement and well-being among Latino first-generation college students. J. Adolesc. Res. 2015, 30, 271-305. [CrossRef]

11. Hsiao, K.P. First-Generation College Students (ERIC ED351079) ERIC Digest, November; ERIC Clearinghouse Products (071); Office of Educational Research and Improvement: Los Angeles, CA, USA, 1992.

12. U.S. Department of Education. Available online: https://www2.ed.gov/programs/idueshsi/definition.html (accessed on 12 December 2017).

13. Turner, C.S.V.; Myers, S.L. Faculty of Color in Academe: Bittersweet Success; Allyn \& Bacon: Boston, MA, USA, 2000.

14. Ravitch, S.M.; Riggan, M. Reason \& Rigor: How Conceptual Frameworks Guide Research; Sage Publications: Thousand Oaks, CA, USA, 2016.

15. Weidman, J.C.; Twale, D.J.; Stein, E.L. Socialization of Graduate and Professional Students in Higher Education: A Perilous Passage? ASHE-ERIC Higher Education Report, Jossey-Bass Higher and Adult Education Series; Jossey-Bass, Publishers, Inc.: San Francisco, CA, USA, 2001; Volume 28, Number 3.

16. Gardner, S.K. Fitting the mold of graduate school: A qualitative study of socialization in doctoral education. Innov. Higher Educ. 2008, 33, 125-138. [CrossRef]

17. Kuh, G.D.; Whitt, E.J. The Invisible Tapestry. Culture in American Colleges and Universities; ASHE-ERIC Higher Education; Report No. 1; Association for the Study of Higher Education: Washington, DC, USA, 1988. 
18. McCoy, D.L.; Winkle-Wagner, R. Bridging the divide: Developing a scholarly habitus for aspiring graduate students through summer bridge programs participation. J. Coll. Stud. Dev. 2015, 56, 423-439. [CrossRef]

19. Thornton, R.; Nardi, P.M. The dynamics of role acquisition. Am. J. Sociol. 1975, 80, 870-885. [CrossRef]

20. Ward, K.A.; Bensimon, E.M. Socialization. In Women in Higher Education: An Encyclopedia; Aleman, A.M.M., Renn, K.A., Eds.; ABC-CLIO: Santa Barbara, CA, USA, 2002; pp. 431-435.

21. Yosso, T.J. Whose culture has capital? A critical race theory discussion of community cultural wealth. Race Ethn. Educ. 2005, 8, 69-91.

22. Gardner, S.K.; Holley, K.A. "Those invisible barriers are real”: The progression of first-generation students through doctoral education. Equity Excell. Educ. 2011, 44, 77-92. [CrossRef]

23. Olive, T. Desire for higher education in first-generation Hispanic college students enrolled in an academic support program: A phenomenological analysis. J. Phenomenol. Psychol. 2008, 39, 81-110. [CrossRef]

24. Terenzini, P.T.; Springer, L.; Yaeger, P.M.; Pascarella, E.T.; Nora, A. First-generation college students: Characteristics, experiences, and cognitive development. Res. Higher Educ. 1996, 37, 1-22. [CrossRef]

25. Lee, J.J.; Sax, L.J.; Kim, K.A.; Hagedorn, L.S. Understanding students' parental education beyond first-generation status. Commun. Coll. Rev. 2004, 32, 1-20. [CrossRef]

26. Phinney, J.S.; Haas, K. The process of coping among ethnic minority first-generation college freshmen: A narrative approach. J. Soc. Psychol. 2003, 143, 707-726. [CrossRef] [PubMed]

27. Fuligni, A.J.; Tseng, V.; Lam, M. Attitudes toward family obligations among American adolescents with Asian, Latin American, and European backgrounds. Child Dev. 1999, 70, 1030-1044. [CrossRef]

28. McConnell, P.J. ERIC Review: What community colleges should do to assist first-generation students. Commun. Coll. Rev. 2000, 28, 75-87. [CrossRef]

29. McCarron, G.P.; Inkelas, K.K. The gap between educational aspirations and attainment for first-generation college students and the role of parental involvement. J. Coll. Stud. Dev. 2006, 47, 534-549. [CrossRef]

30. Gittens, C.B. The McNair program as a socializing influence on doctoral degree attainment. Peabody J. Educ. 2014, 89, 368-379. [CrossRef]

31. Patton, M.Q. Qualitative Research; John Wiley \& Sons, Ltd.: Hoboken, NJ, USA, 2005.

32. Moustakas, C. Phenomenological Research Methods; Sage: Newcastle upon Tyne, UK, 1994.

33. Miles, M.B.; Huberman, A.M.; Saldana, J. Qualitative Data Analysis; Sage: Newcastle upon Tyne, UK, 2013. 